\title{
TWO-DIMENSIONAL COMPUTATIONAL MODELING OF THE SOIL THERMAL BEHAVIOR DUE TO THE INCIDENCE OF SOLAR RADIATION
}

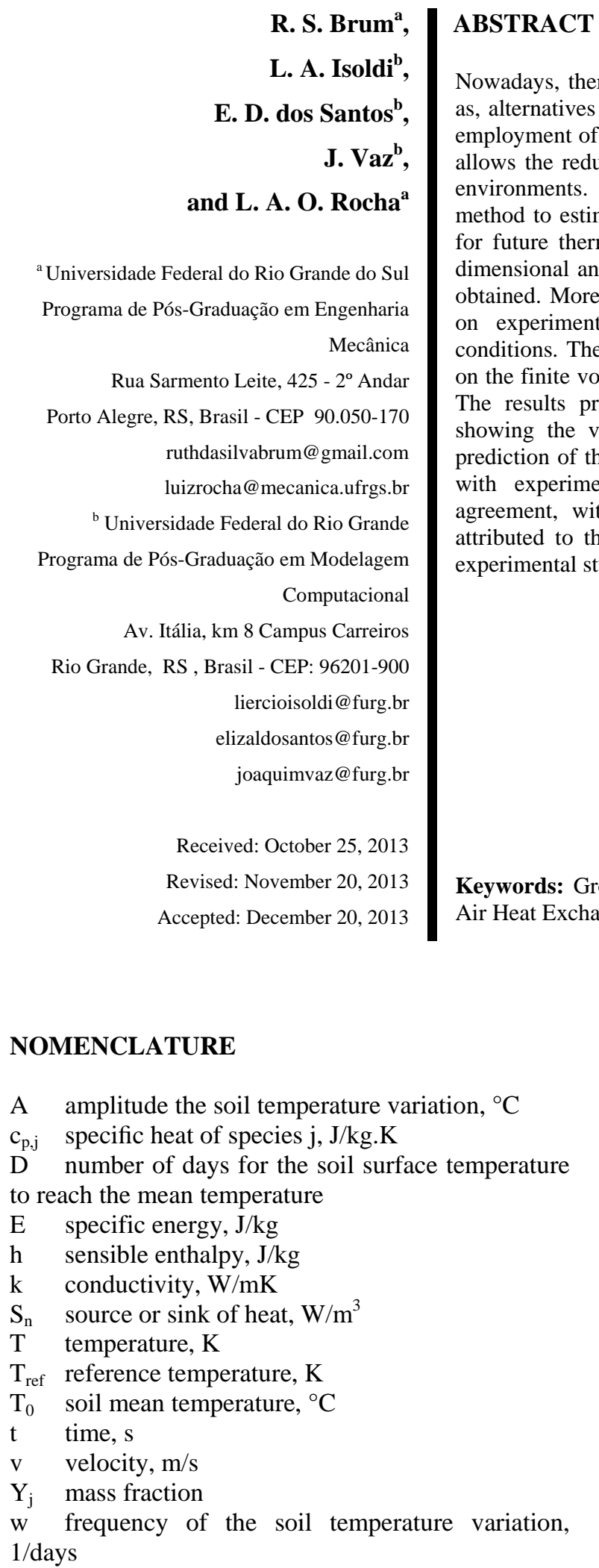

\section{ABSTRACT}

\section{NOMENCLATURE}

A amplitude the soil temperature variation, ${ }^{\circ} \mathrm{C}$

$C_{p, j} \quad$ specific heat of species j, J/kg.K

$\mathrm{D}$ number of days for the soil surface temperature to reach the mean temperature

E specific energy, $\mathrm{J} / \mathrm{kg}$

$\mathrm{h}$ sensible enthalpy, $\mathrm{J} / \mathrm{kg}$

$\mathrm{k}$ conductivity, $\mathrm{W} / \mathrm{mK}$

$\mathrm{S}_{\mathrm{n}}$ source or sink of heat, $\mathrm{W} / \mathrm{m}^{3}$

$\mathrm{T}$ temperature, $\mathrm{K}$

$\mathrm{T}_{\text {ref }}$ reference temperature, $\mathrm{K}$

$\mathrm{T}_{0} \quad$ soil mean temperature, ${ }^{\circ} \mathrm{C}$

$\mathrm{t}$ time, $\mathrm{s}$

$\mathrm{v}$ velocity, $\mathrm{m} / \mathrm{s}$

$\mathrm{Y}_{\mathrm{j}}$ mass fraction

$\mathrm{w}$ frequency of the soil temperature variation, $1 /$ days

Nowadays, there is a focus on finding sustainable energy sources, as well as, alternatives to rationalize the use of electrical energy. In this sense, the employment of Earth-Air Heat Exchangers (EAHE) is one technique which allows the reduction of energy consumption for climatization of buildings environments. The present study shows the evaluation of a numerical method to estimate the ground thermal potential, allowing its applicability for future thermal design of EAHE. The soil domain is considered twodimensional and a transient solution for the thermal behavior of the soil is obtained. Moreover, a soil surface temperature distribution equation based on experimental data is employed to define the domain boundary conditions. The simulations are performed with a numerical method based on the finite volume method, more precisely using the software FLUENT ${ }^{\circledR}$. The results presented an excellent agreement with analytical solutions showing the validity and effectiveness of the computational model for prediction of the soil behavior. The numerical results were also confronted with experimental ones predicted into literature and show a good agreement, with a deviation lower than $14 \%$. The main difference is attributed to the duct presence which is taken into account only for the experimental study.

Keywords: Ground Thermal Potential, Computer Fluid Dynamics, EarthAir Heat Exchangers, Computational Modeling, FLUENT.

\section{Greek symbols}

$\alpha \quad$ thermal diffusivity, $\mathrm{m}^{2} /$ day

$\rho \quad$ density of the fluid, $\mathrm{kg} / \mathrm{m}^{3}$

\section{INTRODUCTION}

The resistance of the climatic adversities and the improvement of the indoor thermal comfort has always been among the goals of the humanity. Therefore, it is possible to state that the weather plays an important role in housing projects. Besides, recently, there is more and more concern to achieve new energy-saving and sustainable technologies.

In general, many air conditioning machines are used inside buildings to heat and cool them in the winter and summer, respectively. This causes an increase in the energy demand, a general concern among building owners, and, particularly, the energy 
concessionaries around peak hours (Hollmuller, 2005).

According to Hollmuller et al. (2005), building designers should consider sustainable alternatives to reduce the need for these machines, such as: the use of sun protection (sunshades, blinds) and thermal isolation systems, control the glass surface in facades, explore ventilation openings and the use of natural lightning. Proper use of all these elements can help to keep a building in a thermal comfort zone. Among renewable energy sources, the solar radiation is an inexhaustible source of heat and light. The solar radiation energy flow which crosses Earth's atmosphere is very high, i.e., nearly $1367 \mathrm{~W} / \mathrm{m} 2$. In one year the planet receives about $1.5 \times 10^{18} \mathrm{kWh}$ of energy, which means more than ten times the world's consumption in the same period (Vaz, 2011).

Part of this energy is lost in the atmosphere, however, more than half of it falls over the earth surface. Due to its huge mass and thermal insulating properties, the Earth's crust works like an immense cyclical inertial reservoir to this energy. For instance, Earth's surface accumulates heat during the day and releases it during the night. In the same way, it accumulates heat during the summer, and releases it during the winter (Vaz et al., 2011; Florides et al., 2011; Jacovides et al., 1996; Mihalakakou et al., 1997).

The Earth-Air Heat Exchangers (EAHE's) take advantage of this thermal inertia. Basically, EAHE is an energy saving air-conditioning technique based on the air circulation through buried pipes or ducts (Mihalakakou et al., 1994; Paepe and Janssens, 2003; Wu et al., 2007; Cucumo et al., 2008; Vaz et al., 2011). Nowadays, an important part of the design of EAHE's can be done through numerical computer simulations based on mathematical models proposed in the literature.

Mihalakakou et al. (1994a) proposed a model for EAHE's which can describe the heat transfer inside the tubes and into the soil accounting for the soil natural thermal stratification. Their computational model was developed within the TRNSYS environment. After that, Mihalakakou et al. (1994b), studied the influence of different ground surface boundary conditions on the efficiency of single and multiple parallel earth tube systems. They compared the cooling potential of systems buried under bare and short-grass covered soils. They found out that short-grass-covered soil could increase the system cooling capacity. This observation could help the improvement of earth tubes performance, and their simulation with advantageous soil surface boundary conditions.

Santamouris (1995) developed an integrated method to calculate the contribution of the EAHE's to reduce the buildings cooling load. The method was based on the principle of balance point temperature and allowed to compute the buildings hourly value balance temperatures, as well as, their daily cooling load. He also used the TRNSYS software.

More recently, $\mathrm{Wu}$ et al. (2007) analyzed EAHE's to reduce the cooling load of buildings in summer. Their numerical model incorporated the turbulent air flow inside the buried pipes. It was validated against experimental investigations in Southern China, where they achieved a daily cooling capacity up to $74.6 \mathrm{kWh}$. The model was implemented on the Computer Fluid Dynamics (CFD) platform PHOENICS. It evaluated the thermal performance and cooling capacity of EAHE's with different operating parameters, such as: the pipe length, the pipe radius, the installation depth and the air flow rate.

Florides et al. (2011) studied the ground temperatures at eight representative sites of Cyprus, in relation to depth, time of the year, geology and altitude, in order to analyze the efficiency of ground coupled heat pumps (GCHP). The data collected indicated a potential for the efficient use of GCHP's leading to significant savings in heating and cooling energy consumption.

Vaz (2011) and Vaz et al. (2011) presented a numerical and experimental study about the use of EAHE's to improve thermal comfort in buildings and to reduce the energy consumption. The experiment was performed in the city of Viamão (RS, Brazil). The results were used to validate a $3 \mathrm{D}$ computer model of EAHE's implemented on the software FLUENT. The transient temperature fields predicted numerically were compared to the experimental ones and the highest difference found was lower than $15 \%$.

The present article aims to present a numerical methodology to predict ground temperature distributions to be used for design of EAHE's. The conservation equation of energy is solved using the finite volume method (Patankar, 1980; Versteeg and Malalasekera, 1995), more precisely the commercial software FLUENT® (FLUENT, 2007). All the results obtained with the present method are compared with the numerical and experimental ones presented in the work of Vaz (2011). The next section outlines the methodology adopted in this paper.

\section{METHODOLOGY}

The numerical simulation of fluid flow, heat transfer, and other related phenomena is known as Computational Fluid Dynamics (CFD). The use of CFD software packages has some advantages, for example, it is possible to highlight the following: time and cost saving to develop new projects; the possibility to analyze complex systems that are hard, or expensive, to be examined in a real-world model; easy-to-use graphical interfaces allowing to define and solve problems with large number of input parameters (Maliska, 2010).

The numerical valuation of ground temperature distributions in this work was simulated in a transient 
two-dimensional mathematical model using the FLUENT CFD package and the GAMBIT mesh generator (Vaz, 2011). The later has helped in the data pre-processing stage; the former has served to pre-processing, processing, and post-processing stages of the analysis.

GAMBIT allows building and discretizing CFD models and other applications. It simplifies the process of designing model domains, defining properties of different regions, discretizing and generating meshes. FLUENT is a CFD software based on the Finite Volume Methods (FVM). It allows to model fluid flow and heat transfer in two or three-dimensional domains, using structured or unstructured meshes (Vaz, 2011).

The mathematical model is defined by the conservation principles of mass, momentum and energy. For the present study, only the soil is solved. Then, only the conservation equation of energy is solved:

$$
\frac{\partial \mathrm{T}}{\partial \mathrm{t}}=\frac{\partial}{\partial \mathrm{x}_{\mathrm{j}}}\left\{\alpha_{\mathrm{s}} \frac{\partial \mathrm{T}}{\partial \mathrm{x}_{\mathrm{j}}}\right\}
$$

being $\mathrm{E}$ the specific energy $(\mathrm{J} / \mathrm{kg})$, $\mathrm{k}$ the conductivity (W/m K), T the temperature (K), $\rho$ is the density of the fluid $\left(\mathrm{Kg} / \mathrm{m}^{3}\right), \quad \mathrm{v}$ is the velocity $(\mathrm{m} / \mathrm{s})$, and $S_{\mathrm{n}}$ $\left(\mathrm{W} / \mathrm{m}^{3}\right)$ stands to any source or sink of heat by conversion of any different kind of energy (electricity, chemical, etc) in thermal energy.

To analyze the temperature field variation due to the depth, a slice of the soil was represented by a 2D mesh. Different from the work of Vaz (2011), a 2D model was used instead of a 3D one to reduce computational costs. The domain covered a soil area of $480 \mathrm{~m}^{2}$, where the upper edge was used to represent the ground surface. Quadrilateral grids were employed to discretize the model. Three meshes were tested through simulations in the FLUENT software and a relative tolerance around $10^{-4}$, comparing the ground temperature at $2 \mathrm{~m}$ depth after 2 years, was established as a sufficient criterion for the mesh independence. Finally, the results presented in this work were obtained with an independent mesh which partitioned the ground in 7680 finite volumes (see Table 1). For the time discretization, it was adopted a time step of $3600 \mathrm{~s}$ (one hour), and a maximum of 200 convergence iterations for each step, which is suggested in the numerical study of Vaz et al. (2011).

In this research, the ground surface temperature variations along the year were modeled by a periodic function. A non-linear least squares method was employed to define such function fitting experimental data from the work of Vaz (2011). Then, this function was inserted in the FLUENT by a User Defined Function (UDF) to represent the temperature boundary conditions on the ground surface. This function is given by:

$$
T(t)=6.28 \sin (0.0172 t+26.24)+18.7
$$

being t the time variable (s).

Table 1. Mesh independence study.

\begin{tabular}{cccc}
$\begin{array}{c}\text { Mesh } \\
\text { Number } \\
(\mathrm{j})\end{array}$ & $\begin{array}{c}\text { Number } \\
\text { of finite } \\
\text { volumes }\end{array}$ & $\begin{array}{c}\text { Ground } \\
\text { Temperature } \\
: \mathrm{T}^{\mathrm{J}}\left({ }^{\circ} \mathrm{C}\right)\end{array}$ & $\begin{array}{c}\text { Relative } \\
\text { Error: }\end{array}$ \\
\hline 1 & 1920 & 19.6566 & - \\
\hline 2 & 7680 & 19.6022 & $1.86 \times 10^{-4}$ \\
\hline 3 & 30720 & 19.6384 & $1.24 \times 10^{-4}$ \\
\hline
\end{tabular}

Regarding the other boundary conditions, the domain sides and bottom were considered thermally insulated by the following reasons. On the sides, the temperature gradient was found to be negligible. Since the domain depth was $15 \mathrm{~m}$, at this depth there is no significant temperature variations due to the incident solar radiation. Concerning initial conditions, the domain was first assumed to be at $18.7^{\circ} \mathrm{C}$, which is the ground mean annual temperature. As it was previously performed in Vaz (2011), the simulations started at 00:00 am on the first of January of 2007.

In the next section, the results are presented and discussed.

\section{RESULTS}

To verify and validate the two-dimensional simulations, the numerical results were compared to an analytical solution and experimental results found in Vaz (2011), respectively. This data collected in 2007 form a database that supports the analysis done in this work. Several digital sensors were used to monitor the temperature variations in the soil (in the depths of $0.05 \mathrm{~m}, 0.3 \mathrm{~m}, 0.5 \mathrm{~m}, 1.0 \mathrm{~m}, 2.0 \mathrm{~m}$ and $3.0 \mathrm{~m}$ ), in the external and internal air, and in the air flux inside the ducts. The sensors accuracy was $\pm 0.1^{\circ} \mathrm{C}$. All measurements were taken at regular intervals of 30 minutes.

The analytical solution of the heat diffusion equation in the soil is obtained from simplifications given in (Moreland, 1976, apud Givoni e Kats, 1985) when the temperature in the soil surface is known. The temperature distribution with respect to the ground depth $(\mathrm{z})$ and the time $(\mathrm{t})$ is given by:

$$
\mathrm{T}(\mathrm{z}, \mathrm{t})=\mathrm{T}_{0}+A \mathrm{e}^{-\mathrm{z} \sqrt{\frac{\mathrm{w}}{2 \alpha}}} \sin \left(\mathrm{w}(\mathrm{t}+\mathrm{D})-\mathrm{z} \sqrt{\frac{\mathrm{w}}{2 \alpha}}\right)
$$

where $\mathrm{T}_{0}\left({ }^{\circ} \mathrm{C}\right)$ is the soil mean temperature, $\mathrm{A}\left({ }^{\circ} \mathrm{C}\right)$ and $\mathrm{w}$ (1/days) are, respectively, the amplitude and the frequency of the soil temperature variation (in annual terms $\left.\mathrm{w}=\frac{2 \pi}{365 \text { days }}\right), \alpha\left(\mathrm{m}^{2} /\right.$ day $)$ is the thermal 
diffusivity and D (days) is the number of days for the soil surface temperature to be equal to its mean.

The soil mean temperature, the thermal diffusivity, and the amplitude of the soil temperature variation, were found by $\mathrm{Vaz}$ (2011) to be, respectively: $\mathrm{T}_{0}=18.7^{\circ} \mathrm{C}, \quad \alpha=0.057 \mathrm{~m}^{2} /$ day, $\mathrm{A}=6.3^{\circ} \mathrm{C}$. Based on the ground temperature data measured in 2007, it is possible to predict the average soil surface temperature $(\mathrm{z}=0)$. The lowest and the highest temperatures are, respectively, $13.5^{\circ} \mathrm{C}$ and $26.1^{\circ} \mathrm{C}$. Moreover, these temperatures occur, respectively, on July 28th and January 26th.

Figures 1 and 2 illustrate the temperatures distributions with the ground depth along different months of the year. They are very similar because the analytical and numerical results agreed within $0.1 \%$. Theoretically, it can be noticed that, as the depth increases the temperatures tend to an average value of $18.7^{\circ} \mathrm{C}$ during all the year.

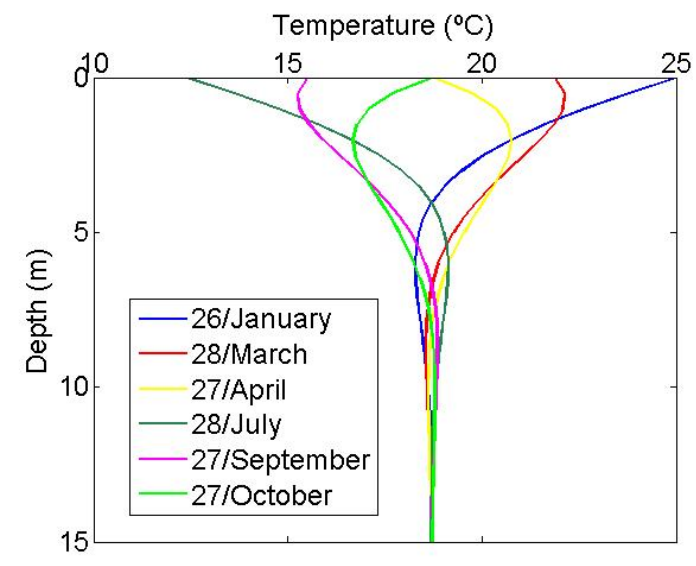

Figure 1. Temperature distributions with the ground depth along the year given by the analytical solutions.

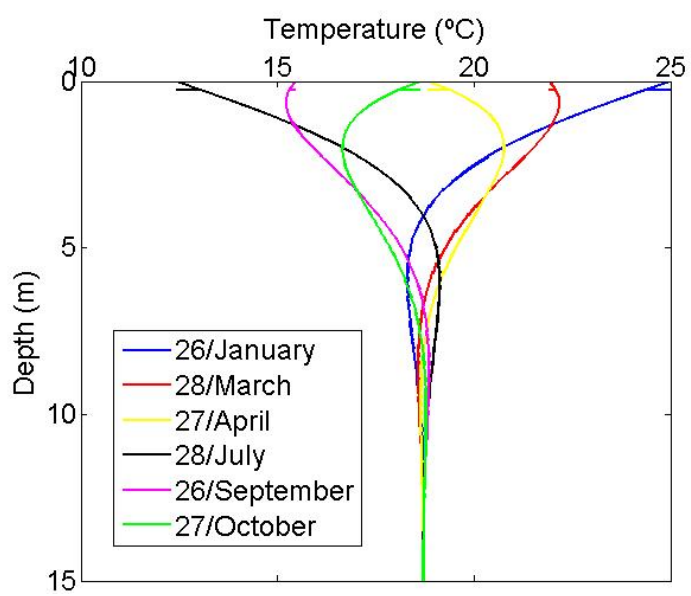

Figure 2. Temperature distributions with the ground depth along the year given by the numerical solutions.

This paper also presents experimental results considering specifically one day in the winter (July 28th) and one in the summer (January 26th), these are shown in the Figs. 3 and 4 . The graphs show again the close agreement between the numerical and analytical solutions. Comparing the numerical and experimental results, there is a qualitative agreement between them. The behavior of these solutions is similar to the experimental data up to the depth of $3 \mathrm{~m}$ (the maximum depth which the temperatures were measured in the soil). The differences in the results reach approximately $3^{\circ} \mathrm{C}$.

It is also important to notice that the analytical and numerical solutions take into account the ground without ducts, while the measurements were done in a ground with ducts. Once the mathematical model is well solved by the present numerical methodology, the difference found between the numerical and experimental results is probably concerned with the influence of the ducts over the thermal behavior of the soil. In this sense, future investigations will be performed to evaluate this influence.

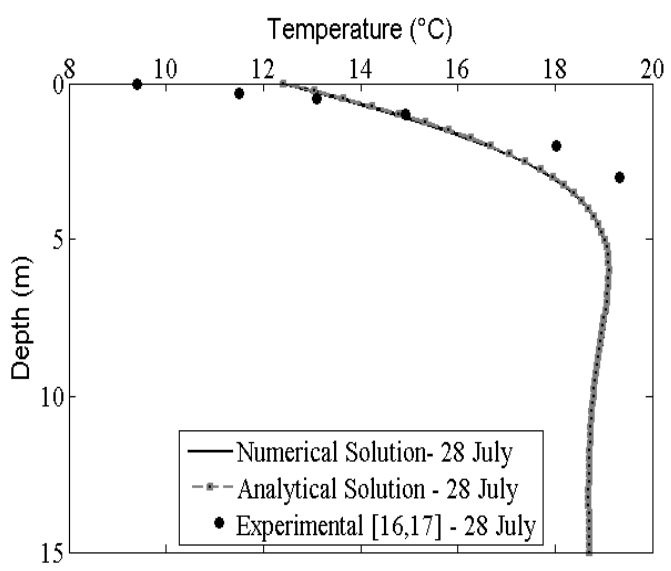

Figure 3. Temperature distribution with the ground depth on July 28th.

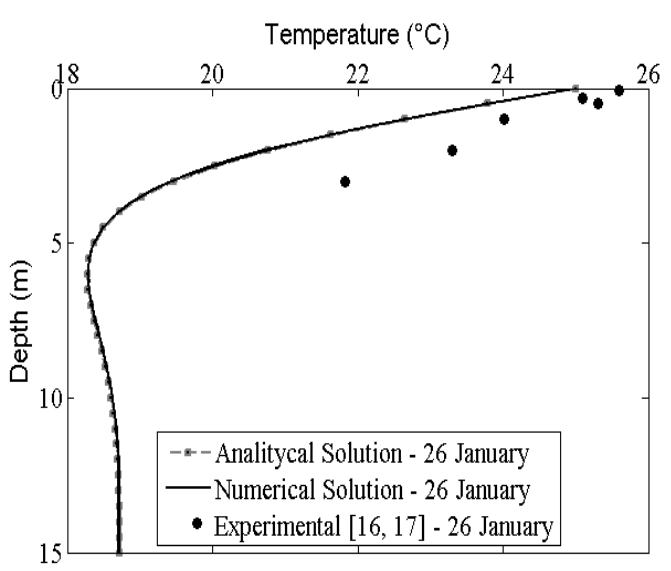

Figure 4. Temperature distribution with the ground depth on January 26th.

Figure 5 displays the ground temperature distribution on this typical winter day in the city of Viamão. As it can be expected, the lower layers of 
the soil are warmer than its surface. More precisely, the ground temperatures increase with the depth until it achieves an average temperature of $18.7^{\circ} \mathrm{C}$. The Fig. 6 shows the temperature distribution in the soil in a typical summer day. On the contrary to the previous case, the lower layers of the soil are colder than its surface. This behavior is in agreement with the previous findings of literature, see for example (Vaz, 2011; Vaz et al., 2011).

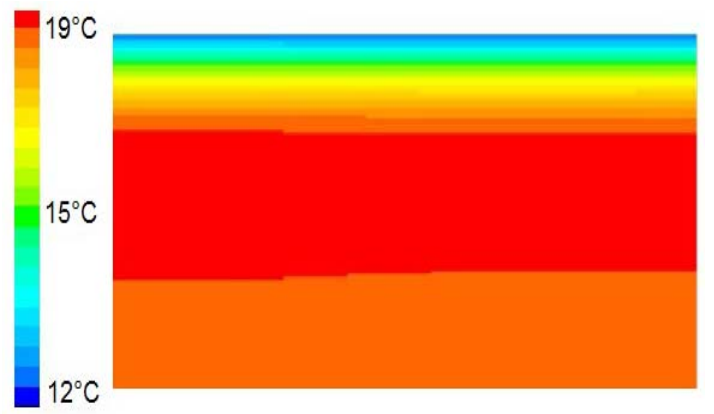

Figure 5. Temperature field topology - July 28th.

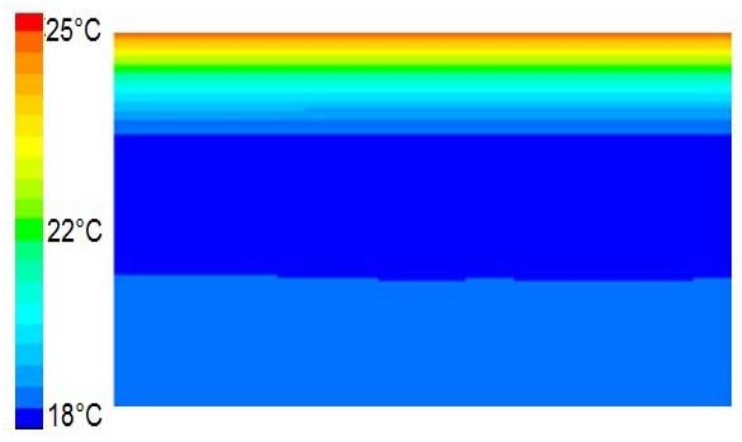

Figure 6. Temperature field topology - January 26th.

The numerical results for the ground temperature at different depths over the time are shown in Fig. 7 (Depth $=0 \mathrm{~m}-5 \mathrm{~m}$ ) and Fig. 8 (Depth $=6 \mathrm{~m}-12 \mathrm{~m}$ ). It can be noticed that as the depth increases the sinusoidal oscillations in the temperature field are smoothed, and they tend to be closer to the soil average temperature. These graphics also show that the ground has a high potential for cooling during the months of December and January. From June to August it can be potentially used for heating. For these extreme situations, the EAHE has the highest contribution for climatization of building environments.

\section{CONCLUSIONS}

In the present work it was evaluated a numerical methodology for evaluation of the thermal behavior of the soil for future implementations on Earth-Air Heat Exchangers (EAHE) for climatization of buildings environments. The simulations were performed with a numerical method based on the finite volume method (Patankar, 1980; Versteeg and
Malalasekera, 1995), more precisely the software FLUENT $^{\circledR}$ (Fluent, 2007). A soil surface temperature distribution equation based on experimental data is employed to define the boundary conditions of domain. Moreover, the soil was considered twodimensional and the transient solution for the thermal field was reached.

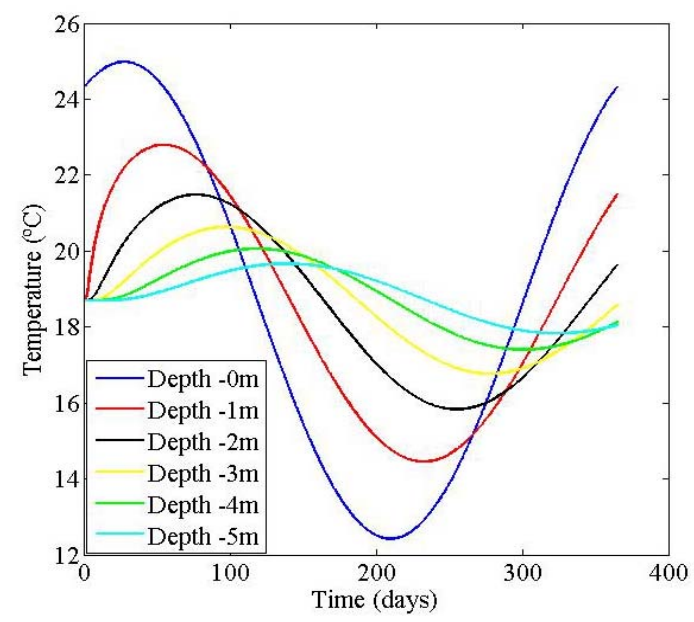

Figure 7. Ground temperature at different depths (0 to $5 \mathrm{~m}$ ) over the time.

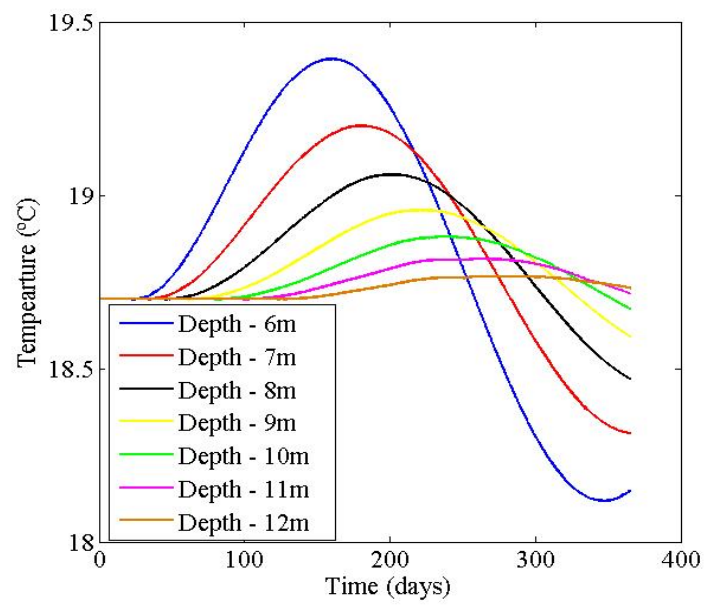

Figure 8. Ground temperature at different depths (6 to $12 \mathrm{~m}$ ) over the time.

The numerical results shown that, the employment of a two-dimensional domain is a very good simplificative hypothesis for the prediction of the ground thermal behavior. The results also shown an excellent agreement between the numerical and analytical predictions for two specific days of winter (July 28th) and summer (January 26th). The numerical predictions were also confronted with experimental results and a good agreement was obtained, a deviation lower than $14 \%$. Once the numerical model solved suitably the mathematical modeling, it was esteemed that the difference is related to the duct presence, which is taken into account only for the experimental study. Future 
studies will be performed in this subject to evaluate the main causes for these differences. Another important observation was that the numerical results obtained here for the thermal behavior as a function of the depth were in close agreement with the previous observations presented in the studies of $\mathrm{Vaz}$ (2011) and Vaz et al. (2011). Thus, the numerical method proved successful for future studies and design of Earth-Air Heat Exchangers (EAHE).

\section{ACKNOWLEDGEMENTS}

The author R. da S. Brum thanks CNPq by her doctor's scholarship. E. D. dos Santos thanks FAPERGS by financial support (Process: 12/1418-4) and L. A. O. Rocha thanks CNPq by research grant.

\section{REFERENCES}

Bejan, A., 1994, Convection Heat Transfer, John Wiley \& Sons.

Cucumo, M., Cucumo, S., Montoro L., and Vulcano A., 2008, A One-Dimensional Transient Analytical Model for Earth-to-Air Heat Exchangers, Taking into Account Condensation Phenomena and Thermal Perturbation from the Upper Free Surface as well as Around the Buried Pipe, International Journal of Heat and Mass Transfer, Vol. 51, pp. 506-516.

Florides, G. A., Pouloupatis, P. D., Kalogirou, S., Messaritis, V., Panayides, I., Zomeni, Z., Partasides, G., Lizides, A., Sophocleous, E., and Koutsoumpas, K., 2011, The Geothermal Characteristics of the Ground and the Potential of Using Ground Coupled Heat Pump sin Cyprus, Energy, Vol. 36, No. 8, pp. 5027-5036.

FLUENT, 2007, FLUENT User's Guide, ANSYS Inc.

Givoni, B., and Katz, L., 1985, Earth Temperatures and Underground Buildings, Energy and Buildings, Vol. 8, No. 1, pp. 15-25.

Hollmuller, P., Lamberts, R., Westphal, F. S., Ordenes, M. M., and Carlo, J. C., 2005, Potencial da Ventilação Inercial para Resfriamento Passivo em Climas Brasileiros, in: VIII Encontro Nacional sobre Conforto no Ambiente Construído e IV Conferência Latino-americana sobre Conforto e Desempenho Energético de Edificações, Alagoas, pp. 1-11. (in Portuguese)

Jacovides, C. P., Mihalakakou, G., Santamouris, T. M., and Lewis, J. O., 1996, On the Ground Temperature Profile for Passive Cooling Applications in Buildings, Solar Energy, Vol. 48, No. 3, pp. 167175.

Maliska, C. R., 2010, Transferência de Calor e Mecânica dos Fluidos Computacional, LTC - Livros Técnicos e Científicos Editora S.A.. (in Portuguese) Mihalakakou, G., Santamouris, M., Asimakopoulos, D., and Papanikolaou, N. F., 1994a, Modeling the Thermal Performance of Earth-to-air
Heat Exchangers, Solar Energy, Vol. 53, No. 3, pp. 301-305.

Mihalakakou, G., Santamouris, M., Asimakopoulos, D., and Papanikolaou, N. F., 1994b, Impact of Ground Cover on the Efficiencies of Earthto-air Heat Exchangers, Applied Energy, Vol. 48, pp. 19-32.

Mihalakakou, G., Santamouris, M., Lewis, M. O., and Asimakopoulos, D., 1997, On the Application of the Energy Balance Equation to Predict Ground Temperature Profiles, Solar Energy, Vol. 60, pp. 181190.

Moreland, F., 1976, An Alternative to Suburbia, in: Proceedings of Conference on Alternatives in Energy Conservation: The use of Earth Covered Buildings, Fort Worth, Texas, pp. 203-204.

Paepe, M. D., and Janssens, A., 2003, ThermoHydraulic Design of Earth-Air Heat Exchangers, Energy and Buildings, Vol. 35, No. 4, pp. 389-397.

Patankar, S. V., 1980, Numerical Heat Transfer and Fluid Flow, Hemisphere Publishing Corporation.

Vaz, J., 2011, Estudo Experimental e Numérico Sobre o uso do Solo como Reservatório de Energia para o Aquecimento e Resfriamento de Ambientes Edificados, Doctoral Thesis, Universidade Federal do Rio Grande do Sul, Porto Alegre, RS. (in Portuguese) Vaz, J., Sattler, M. A., dos Santos, E. D., and Isoldi, L. A., 2011, Experimental and Numerical Analysis of an Earth-Air Heat Exchange, Energy and Buildings, Vol. 43, No. 9, pp. 2476-2482.

Versteeg H. K., and Malalasekera, W., 2007, An Introduction to Computational Fluid Dynamics, Pearson Education Limited.

Wu, H., Wang, S., and Zhu, D., 2007, Modelling and Evaluation of Cooling Capacity of Earth-air-pipe Systems, Energy Conversion and Management, Vol. 48, pp. 1462-1471. 